\title{
IMPLEMENTASI SISTEM INFORMASI KEHADIRAN SISWA PADA SMKN 2 KABUPATEN TANGERANG
}

\author{
Aris Martono ${ }^{1}$ \\ Eko Arjun Setyawan ${ }^{2}$ \\ Alda Dwi Pambudi ${ }^{3}$ \\ Dosen STMIK Raharja ${ }^{1}$, STMIK Raharja Jurusan Sistem Informasi ${ }^{2}$, \\ STMIK Raharja Jurusan Sistem Informasi ${ }^{3}$ \\ Jl. Jendral Sudirman No. 40, Modernland, Tangerang \\ Email : aris.martono@ raharja.info eko.arjun@raharja.info alda.dwi@ raharja.info
}

\begin{abstract}
ABSTRAK
Tujuan dari penelitian ini adalah untuk memantau kehadiran siswa dengan menggunakan sistem berbasis website di Lingkungan SMKN 2 Kabupaten Tangerang. Permasalahan sistem kehadiran siswa pada SMKN 2 Kabupaten Tangerang ini masih menggunakan sistem yang manual dengan jumlah siswa yang cukup banyak yaitu 2320 siswa. Penggunaan sistem kehadiran ini menyulitkan karena melibatkan banyak pihak, belum lagi memakan proses yang cukup panjang, Sehingga keakuratan data belum terjamin karena sering terjadi kecurangan dalam pelaksanaanya. Penelitian ini dilakukan dengan cara observasi, wawancara, dan juga studi pustaka. Menggunakan analisis SWOT untuk menemukan faktor-faktor kekurangan dan kelebihan sistem guna mengatasi kelemahan serta menambah kelebihan. Untuk mengetahui kebutuhan sistem, dilakukan analisis kebutuhan elisitasi dan menghasilkan 27 kebutuhan fungsional sistem dan 2 kebutuhan nonfungsional. Pembuatan model sistem dengan Unified Modelling Language (UML) untuk menggambarkan rancangan sistem konseptual dan rancangan sistem detail. Dalam perancangan prototype, tampilan layar sistem dibuat berlevel seperti struktur menu yang terdiri dari menu login, rekam, proses, laporan, utility, dan logout. Dengan adanya sistem ini memudahkan para pengguna untuk mengoperasikan.
\end{abstract}

Kata Kunci : Sistem Kehadiran, kebutuhan fungsional, sistem konseptual, sistem detail

\begin{abstract}
The purpose of this study is to monitor student attendance by using a website-based system in SMKN 2 Tangerang District. Problem of student attendance system at SMKN 2 of Tangerang Regency still use manual system with enough number of student that is 2320 students. The use of attendance system is difficult because it involves many parties, not to mention eat a long process, so the accuracy of data is not guaranteed because of frequent fraud in the implementation. This research is done by observation, interview, and also literature study. Using the SWOT analysis to find the underlying and system overload factors to overcome weaknesses and add strengths. To find out system requirement, elicitation requirement analysis was performed and result 27 functional requirement of system and 2 non-functional requirement. System modeling with Unified Modeling Language (UML) to illustrate the conceptual system design and detailed system design. In designing the prototype, the display of the system screen is made in a level like menu structure which consists of menu login, record, process, report, utility, and logout. With this system allows users to operate.
\end{abstract}

Keywords: Attendance System, functional requirements, conceptual system, detail system 


\section{PENDAHULUAN}

\section{Latar Belakang}

Pengolahan sebuah informasi sangat bergantung dengan teknologi dan sistem pengolah informasi yang baik, agar pengolahan infomasi dapat efektif dan efisien. Demikian kecenderungan yang banyak terjadi pada instansi pendidikan di seluruh Indonesia saat ini. Yang mana maju pesat atau mundurnya sangat bergantung kepada informasi yang ditangani dengan baik. Dalam hal penanganan informasi SMKN 2 Kabupaten Tangerang selama ini masihlah menggunakan sistem yang manual, yang mana banyak kekhawatiran akan banyak kecurangan atau kesalahan yang terjadi dalam pelaksanaanya, pada satu contoh penanganan sistem kehadiran siswa yang masih manual, juga melibatkan banyak pihak dikhawatirkan terjadi kerancuan data ataupun data kurang valid. guna meminimalkan kemungkinan terjadi kecurangan atau kesalahan data, maka penelitian ini dilakukan dengan mengimplementasi kan Sistem Informasi Kehadiran Siswa Pada SMKN 2 Kabupaten Tangerang.

\section{Permasalahan}

Berdasarkan latar belakang masalah yang diuraikan diatas, terdapat permasalahan yang terjadi yaitu Sistem kehadiran siswa yang berjalan pada saat ini masih menggunakan sistem yang manual, juga karena melibatkan banyak pihak dalam pelaksanaanya, serta membutuhkan waktu yang cukup lama, terkadang data yang dihasilkan pun kurang akurat atau tidak valid. Sehingga sistem kehadiran yang saat ini bisa dikatakan masih belum efektif dan juga efisien.

\section{METODE PENELITIAN}

\section{Metode Pengumpulan Data}

Ada beberapa metode pengumpulan data yang dilakukan dalam penelitian ini diantaranya observasi yaitu mengumpulkan data mengenai cara kerja sistem, kelebihannya, serta kekurangannya secara langsung untuk mendapatkan data secara relevan. Wawancara juga untuk mengumpulkan data dengan cara melihat permasalahan yang ada dari sudut pandang si pemakai baik kelebihan sistem maupun kekurangannya. Studi pustaka untuk mengumpulkam beberapa teori yang berhubungan dengan penelitian yang sedang dilakukan Teknik pengumpulan data yang digunakan untuk mencari ataupun mengumpulkan data serta mengolah informasi yang diperlukan yaiut metode observasi, metode wawancara dan metode studi pustaka.

\section{Metode Analisis Sistem}

Untuk menganalisis kinerja dari sistem yang berjalan maka perlu dilakukan analisis terlebih dahulu terhadap organisasi terkait, prosedur penerapan sistem, input maupun output yang dihasilkan oleh sistem. Dalam hal ini metode analisis sistem menggunakan metode SWOT dimana metode SWOT ini lebih berfokus pada kekutan dari sistem yang diteliti (strenght), kelemahan dari sistem diteliti (weakness), peluang dari sistem yang diteliti (oppurtunity), dan ancaman dari sistem yang diteliti (threats). Dengan menggunakan metode SWOT di atas kita dapat mengetahui kekuatan, kelemahan, peluang, serta ancaman dari 
sistem yang di teliti sehingga kita dapat menentukan langkah yang harus diambil guna memaksimalkan sistem berjalan agar lebih efektif dan efisien.

\section{Metode Perancangan}

Perancangan sistem merupakan tahap selanjutnya setelah menganalisa sistem. Setelah mendapatkan gambaran dengan jelas tentang apa yang akan dikerjakan pada tahap analisa sistem, maka dilanjutkan dengan membuat rancangan sistem, baik mendesain sistem, maupun memasukan fungsi yang harus terdapat nantinya pada sistem tersebut. oleh karena itu dalam perancangan sistem digunakan, Visual Paradigm for UML Interprise Edition merupakan software yang akan digunakan untuk men-design dan membuat suatu model diagram, Xampp Package untuk paket pendukung pemrograman MySql, PHP dan PHP My Admin, dan Sublime Text merupakan software yang digunakan untuk men-design web yang akan dibuat.

\section{Metode Pengujian}

Pengujian adalah tahap yang harus dilakukan sebelum sistem diimplementasikan, tentunya setelah sistem tersebut selesai dibuat. Dalam penelitian ini ada 2 metode pengujian yang digunakan yaitu, blackbox testing. Blackbox Testing adalah metode uji coba yang memfokuskan pada fungsional software. Karena itu ujicoba blackbox memungkinkan pengembangan software untuk membuat himpunan kondisi input yang akan melatih seluruh syarat-syarat fungsional suatu program.

Metode pengujian blackbox berusaha untuk menemukan kesalahan dalam beberapa kategori, diantaranya: fungsi-fungsi yang salah atau hilang, kesalahan interface, kesalahan dalam struktur data atau akses database eksternal, kesalahan performa, kesalahan inisialisasi, dan terminasi.

\section{KAJIAN PUSTAKA}

\section{Kehadiran}

Menurut KBBI ( Kamus Besar Bahasa Indonesia ) kehadiran adalah adanya seseorang, sekumpulan orang) pada suatu tempat.

\section{Analisis sistem}

Menurut Rahmat Taufiq (2013:155), "Analisa sistem adalah suatu kegiatan mempelajari sistem (baik sistem manual ataupun sistem yang sudah terkomputerisasi) secara keseluruhan mulai dari menganalisa sistem, masalah, desain logic dan memberikan keputusan dari hasil analisa tersebut".

\section{Analisis Masalah}

Prosedur sistem kehadiran yang berjalan pada saat ini yaitu dengan cara membuat draft absensi menggunakan Ms. Excel berdasarkan data jumlah siswa dan kelas dan jurusanya, dalam pelaksanaanya pun masih kurang pengawasan sehingga pada saat perekapan data sering ditemui kerancuan data yang terjadi, baik data yang kurang akurat maupun memang data yang telah dimanipulasi. 


\section{LITERATURE REVIEW}

Dalam upaya perlu dilakukan kajian pustaka sebagai salah satu dari penerapan metode penelitian yang akan dilakukan. Diantaranya adalah mengidentifikasikan kesenjangan, menghindari pembuatan ulang, mengidentifikasikan metode yang pernah dilakukan, serta mengetahui orang lain yang spesialisasi dan area penelitian yang sama dibidang ini. Berikut bebrapa Literature review yang berhubungan dengan penelitian ini :

1. Penelitian yang dilakukan oleh Heri Kuswara dan Deni Kusmana dari AMIK BSI Jakarta dan STMIK Nusa Mandiri Jakarta, yang berjudul "Sistem Informasi Absensi Siswa Berbasis Web Dengan SMS Gateway Pada Sekolah Menengah Kejuruan Al - Munir Bekasi”, pada tahun 2017. Dengan menggunakan pengembangan perangkat lunak waterfall, peneliti mencoba membangun sebuah sistem informasi absensi siswa berbasis web dengan sms gateway pada sekolah menengah kejuruan al-munir bekasi menggunakan bahasa pemrograman php dan xampp sebagai web server serta MySql sebagai databasenya sehingga proses input dan olah data lebih cepat. Dengan adanya aplikasi ini diharapkan dapat membantu pihak sekolah dan siswa dalam proses absensi siswa.

2. Penelitian yang dilakukan oleh Yoni Widhiarso dan Berliana Kusuma Riasti, yang berjudul "Rancang Bangun Sistem Informasi Nilai Akademik dan Presensi Siswa Berbasis SMS Gateway pada SDN Tulakan III ”, pada tahun 2013. Tujuan utama penelitian ini adalah pembuatan Sistem Informasi nilai akademik dan presensi siswa berbasis sms gateway. Metode yang diambil penulis yaitu dengan melaksanakan observasi, wawancara, Studi kepustakaan, Analisis dan perancangan Sistem Informasi dilanjutkan dengan Pembuatan Sistem Informasi nilai akademik dan presensi siswa berbasis sms gateway. Hasil dari penelitian ini adalah memberikan kemudahan bagi orang tua siswa untuk mengetahui nilai dan presensi putera/puterinya di sekolah serta memberikan kemudahan bagi pihak sekolah dalam penyampaian nilai dan presensi siswa kepada orang tua siswa

3. Penelitian yang dilakukan oleh Wahyu Adam M.Eng.Sc dan Lamhot Sagala dari STMIK LPKIA, yang berjudul " Sistem Absensi Menggunakan Teknologi RFID ", pada tahun 2014. Tugas akhir ini bertujuan untuk merancang sebuah prototipe sistem absensi RFID yang terintegrasi dengan database untuk mendukung program peningkatan sikap displin karyawan sebagai langkah awal dari peningkatan kinerja kerja perusahaan secara keseluruhan.Prototipe RFID sistem absensi ini terdiri dari beberapa komponen utama, yaitu tag yang akan digunakan sebagai pengganti ID card dan reader yang digunakan untuk membaca informasi menyangkut kehadiran karyawan, integrasi database pada sistem ini akan memungkinkan dua untuk langsung disimpan secara otomatis ke dalam database.Hasil dari tugas akhir ini adalah sebuah prototype dari RFID sistem absensi yang memiliki fungsi untuk menyimpan data kehadiran karyawan, dengan jarak baca maksimum $3 \mathrm{~cm}$ dengan peluang keberhasilan.

4. Penelitian yang dilakukan oleh Muchamad Nuh, yang berjudul " Pembangunan Sistem Informasi Presensi Siswa Pada Sekolah Menengah Atas (SMA) Negeri 1 Rembang Berbasis Fingger Print”, pada tahun 2012. Sistem ini dirancang dengan menggunakan finger print. Sedangkan bahasa pemrograman yang digunakan adalah PHP dan database MySQL. Sistem ini dirancang dan di bangun untuk mempermudah penyampaian informasi. Tujuan utama sistem ini adalah untuk memudahkan para siswa untuk presensi. Dapat disimpulkan Pembangunan Sistem Informasi Presensi ini dapat menggantikan cara konfesional yang sebelumnya digunakan pada SMA Negeri 1 Rembang menjadi Sistem Informasi Presensi Siswa yang Berbasis Finger Print. 
5. Penelitian yang dilakukan oleh Syarah dan Sri Rahayu dan Arie Fiyan Wira Wisena, yang berjudul "Perancangan Sistem Informasi Absensi Staf dan Guru Pada SMA Bina Insani Berbasis Web ", pada tahun 2012. Analisa sistem informasi dilakukan melalui tahapan analisis, kemudian merancang Sistem yang akhirnya dapat menjadi solusi dari permasalahan user dalam Sistem Absensi ini. Hasil rancangan Sistem digambarkan dengan menggunakan Unified Modeling Language (UML) dan diaplikasikan dengan bahasa pemrograman berbasis web.

Hasil evaluasi judul penelitian ini dengan lima penelitian sebelumnya bahwa penelitian ini berbeda lokasi penelitian dimana setiap sekolah memiliki karakteristik sendirisendiri sehingga penerapan di sekolah hasilnya berbeda pula.

\section{HASIL DAN PEMBAHASAN}

\section{Analisis SWOT}

Berikut hasil analisis SWOT dari sistem kehadiran yang berjalan.

Tabel 1. Analisis SWOT Sistem Kehadiran Siswa

\begin{tabular}{|c|l|}
\hline \multicolumn{2}{|c|}{ Faktor Internal } \\
\hline Kekuatan (S) & $\begin{array}{l}\text { Mudah dalam membuat buku absensi juga waktu yang } \\
\text { diperlukan untuk membuatnya cukup sedikit. }\end{array}$ \\
\hline Kelemahan (W) & $\begin{array}{l}\text { Dalam jangka panjang dengan jumlah siswa yang } \\
\text { banyak juga akan memakan biaya yang cukup besar. }\end{array}$ \\
\hline Peluang (O) & $\begin{array}{l}\text { Faktor Eksternal } \\
\text { menangani data nilai yang efisien dan realtime } \\
\text { Pemberkasan absensi yang akan lebih mudah dan } \\
\text { efektif juga efisien dan } \\
\text { Belum banyak sekolah yang menggunakan sistem ini. }\end{array}$ \\
\hline Ancaman (T) & $\begin{array}{l}\text { Akan banyak sekolah dengan teknologi informasinya } \\
\text { lebih maju sehingga akan terjadi persaingan. }\end{array}$ \\
\hline
\end{tabular}

\section{PEMECAHAN MASALAH}

Dalam upaya untuk mencari solusi demi mengatasi kekurangan dari kinerja sistem kehadiran yang ada saat ini, terpikirlah sebuah solusi berasal dari hasil analisa dan hasil wawancara yaitu dengan membuat sistem informasi kehadiran siswa berbasis website, guna memudahkan dalam pemantauan pelaksanaan sistem kehadiran, juga karna dapat memudahkan berbagai pihak dalam hal pelaksanaan, perekapan data dan juga pembuatan laporan.

\section{Diagram Rancangan Sistem}

Berikut adalah rancangan diagram dari sistem yang diusulkan. 


\section{Use Case Diagram}

Berikut adalah rancangan use case diagram dari sistem kehadiran siswa.

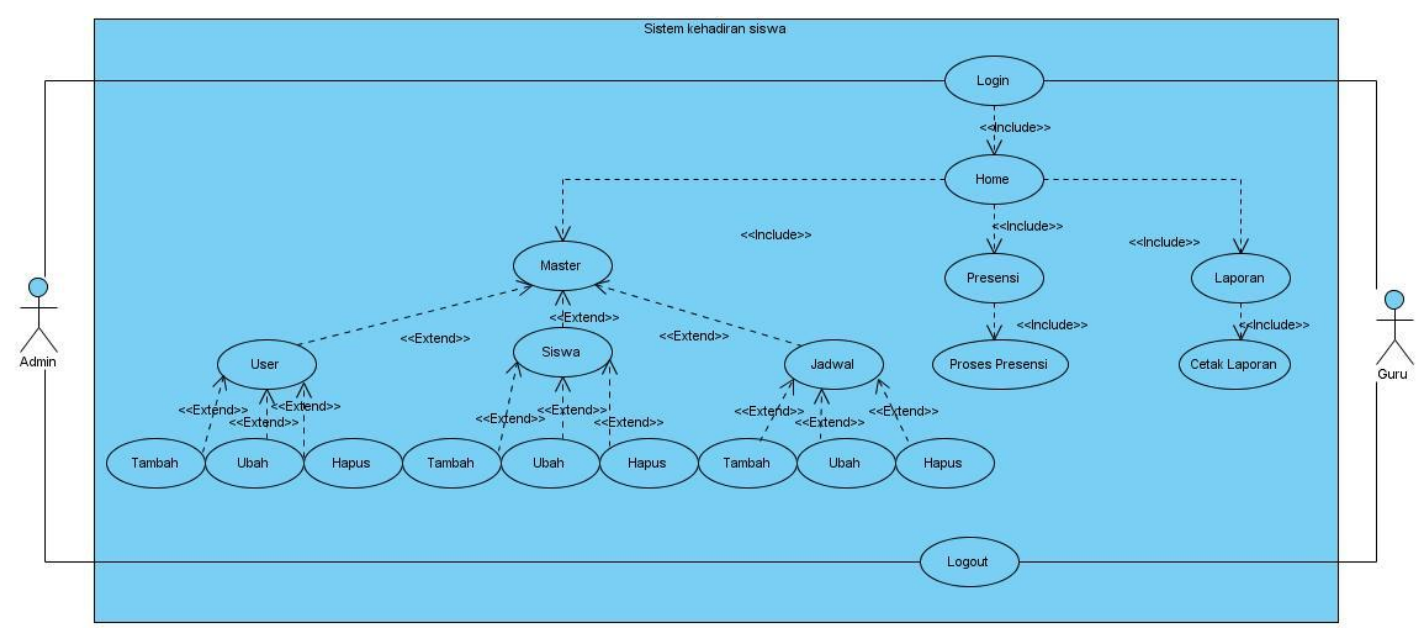

Gambar 1. Use Case Diagram

\section{Activity Diagram}

Berikut adalah rancangan activity diagram dari sistem kehadiran siswa.

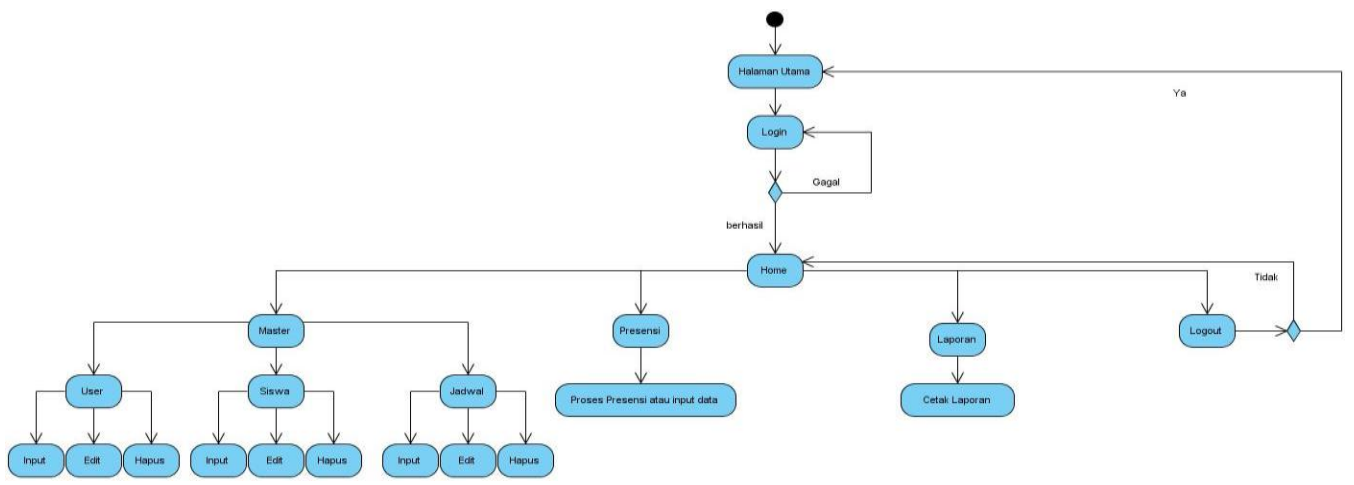

Gambar 2. Activity Diagram Sistem Kehadiran Siswa

\section{Sequence Diagram}

Berikut adalah rancangan sequence diagram dari sistem kehadiran siswa.

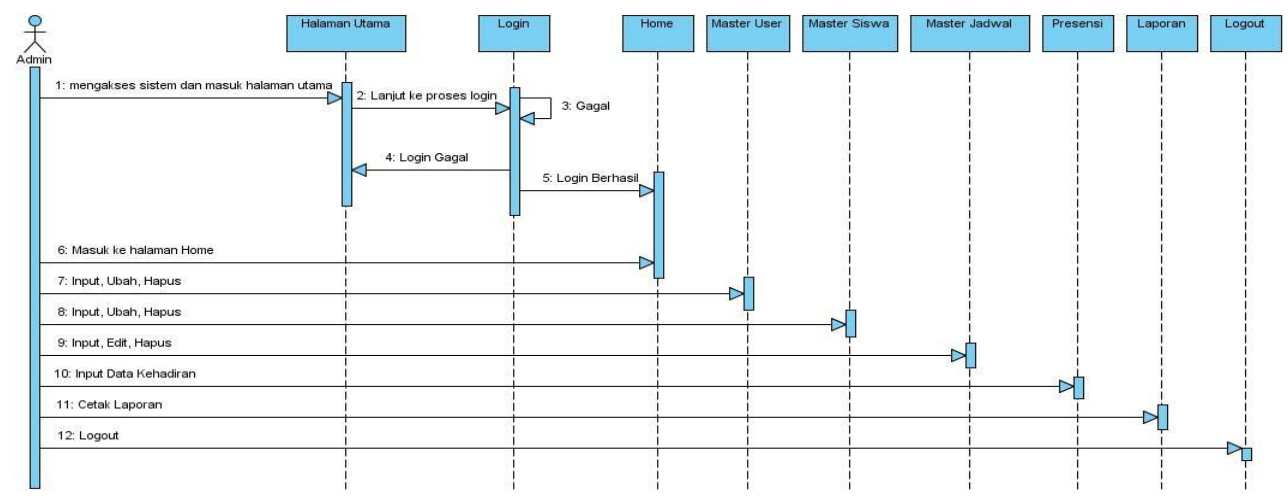

Gambar 3. Sequence Diagram Sistem Kehadiran Siswa 


\section{Class Diagram}

Berikut adalah rancangan class diagram dari sistem kehadiran siswa.

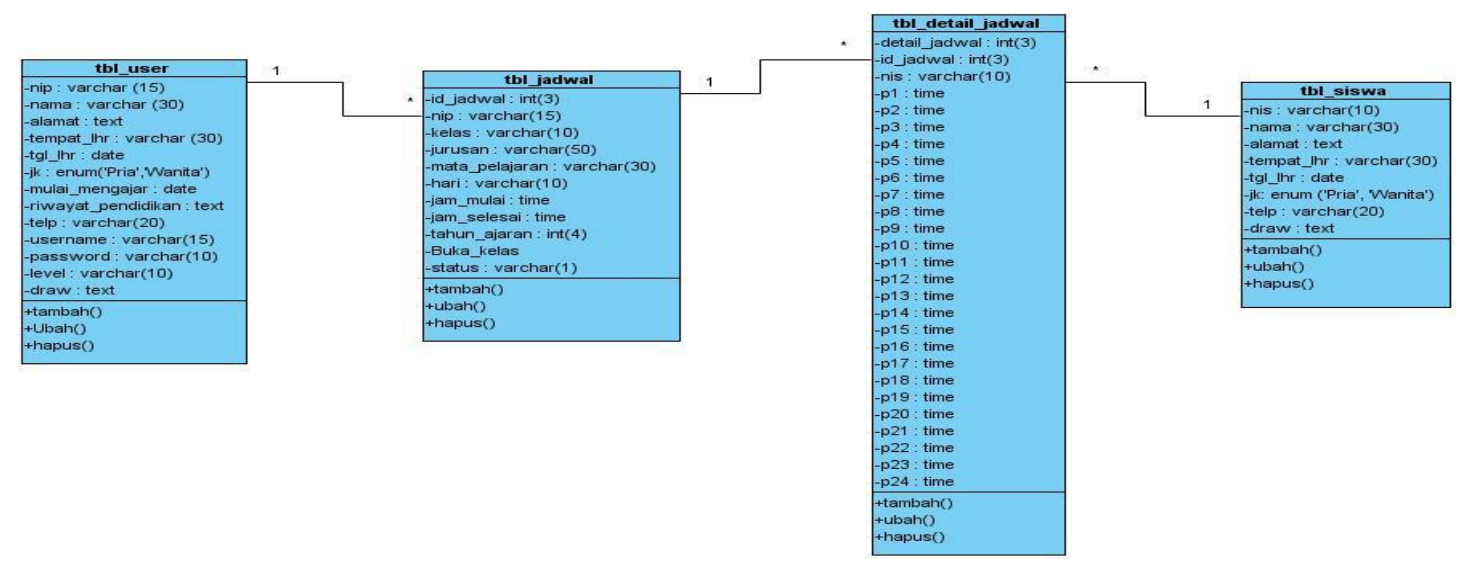

\section{Gambar 4. Sequence Diagram Sistem Kehadiran Siswa}

\section{IMPLEMENTASI}

Dibawah ini terdapat beberapa prototype dari rancangan sistem yang dibuat diantaranya prototype login, prototype home, prototype menu user, prototype menu siswa, prototype menu jadwal, Prtotype presensi, prototype laporan. Prototype ini dibuat guna menggambarkan kinerja dari sistem yang dibuat sesuai dengan user requirement.

\section{Tampilan Login}

Tampilan ini berisi form untuk user login ke dalam sistem.

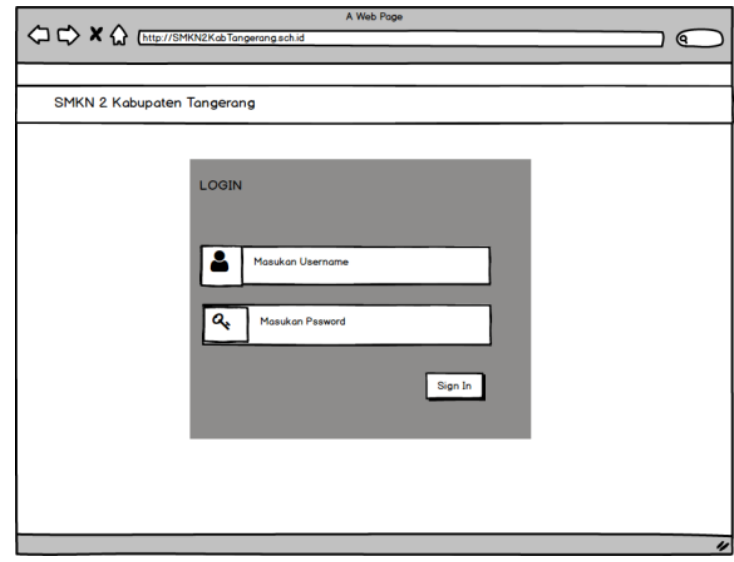

\section{Gambar 5. Tampilan Login}

\section{Tampilan Home}

Tampilan ini berisi verifikasi untuk masuk sistem yaitu menu login (lihat gambar 2 . dibawah ini) 


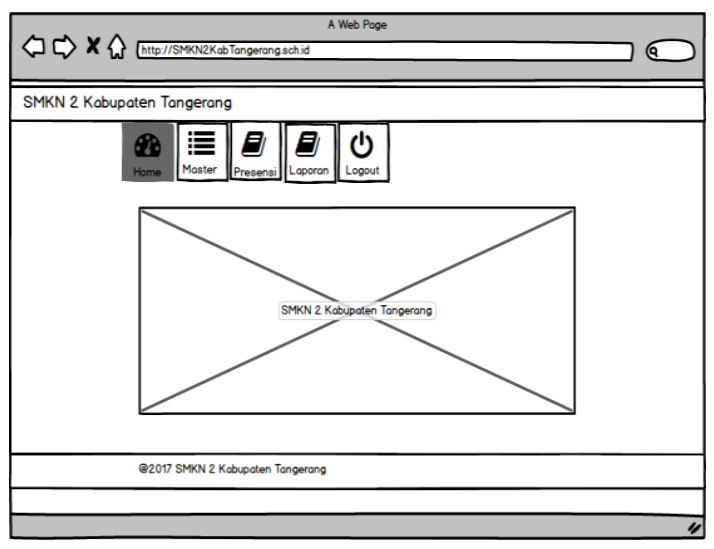

Gambar 6. Tampilan Home

\section{Tampilan Master}

Tampilan ini adalah home yang berisi tentang informasi umum mengenai SMKN 2 Kabupaten Tangerang, serta penghubung antar semua menu yang ada didalam sistem.

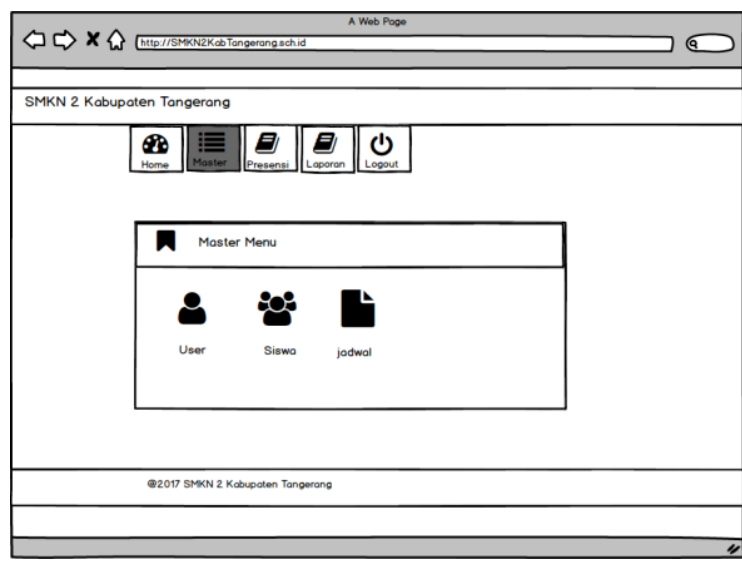

Gambar 7. Tampilan Master

\section{Tampilan Menu User}

Tampilan ini berisi halaman yang digunakan untuk mengelola data user, baik tambah, ubah, ataupun hapus.

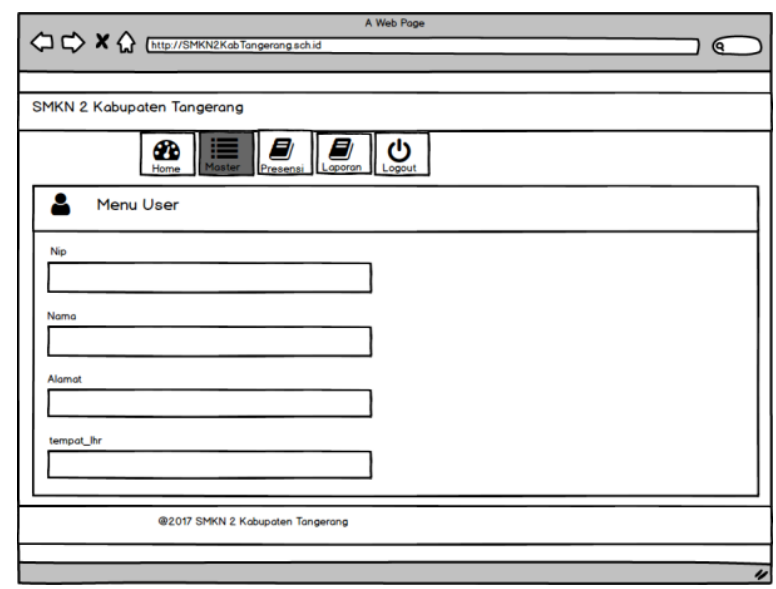

Gambar 8. Tampilan Menu User 


\section{Tampilan Menu Siswa}

Tampilan ini berisi halaman yang digunakan untuk mengelola data siswa, baik tambah, ubah, ataupun hapus.

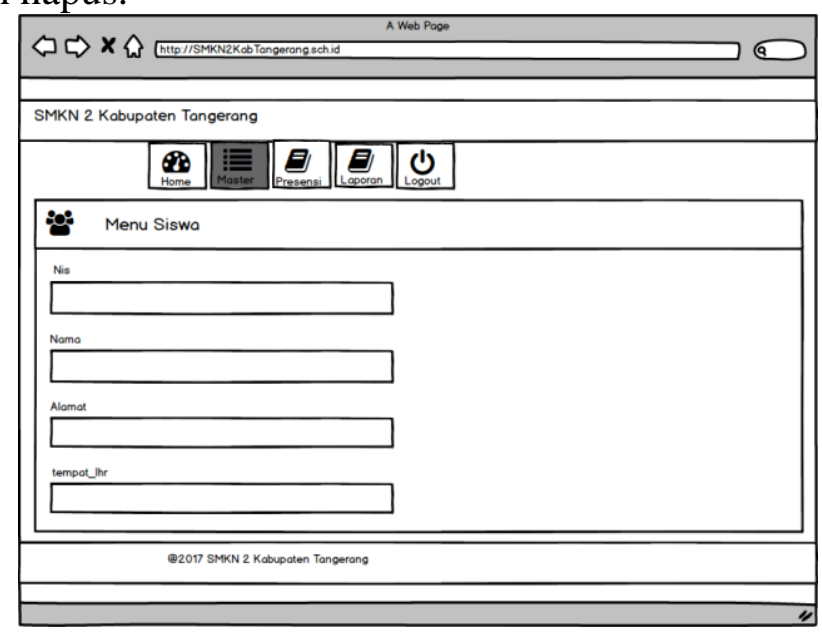

Gambar 9. Tampilan Menu Siswa

\section{Tampilan Menu Jadwal}

Tampilan ini berisi halaman yang digunakan untuk mengelola data jadwal, baik tambah, ubah, ataupun hapus.

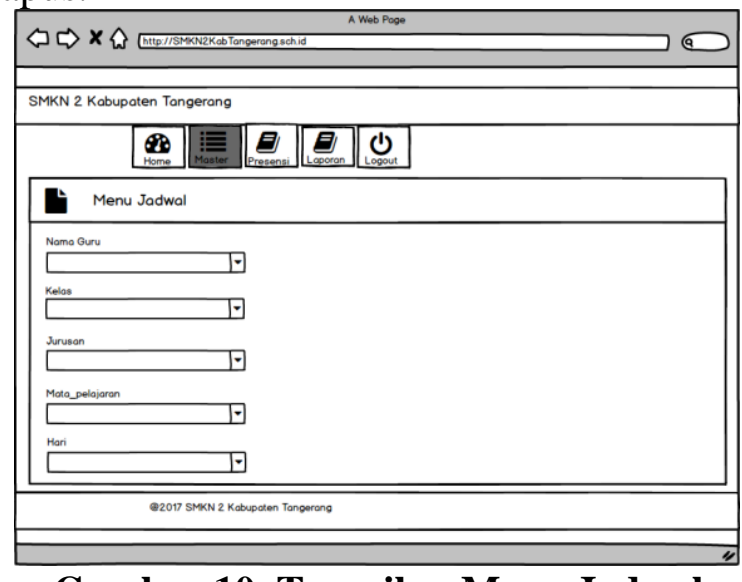

Gambar 10. Tampilan Menu Jadwal

\section{Tampilan Menu Presensi}

Tampilan ini berisi halaman yang digunakan untuk menginput data kehadiran. 


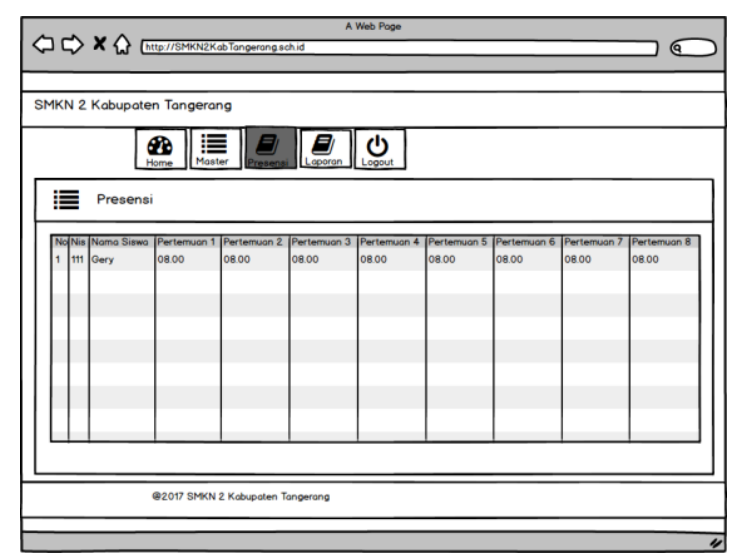

Gambar 11. Tampilan Menu Presensi

\section{Menu Laporan Presensi}

Tampilan ini berisi halaman yang digunakan untukmengelola data kehadiran, baik inpiut, ubah, maupun hapus.

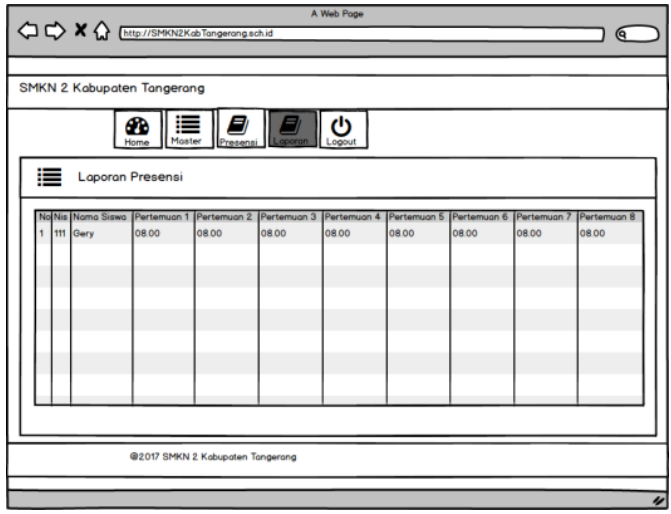

Gambar 12. Tampilan Laporan Presensi

\section{Tampilan Menu Logout}

Tampilan ini berisi halaman yang digunakan untukmengelola data kehadiran, baik inpiut, ubah, maupun hapus.

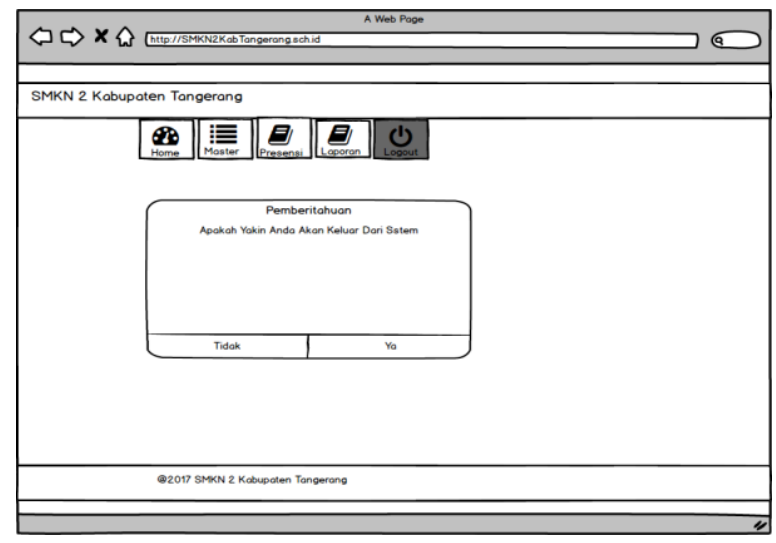

Gambar 13. Tampilan Logout 


\section{KESIMPULAN DAN SARAN}

\section{KESIMPULAN}

Berdasarkan pembahasan yang diuraikan di atas, maka dapat diambil kesimpulan sebagai berikut:

1. Sistem kehadiran siswa di SMKN 2 Kabupaten Tangerang belumlah sepenuhnya terkomputerisasi, sistem kehadiran siswa dilakukan secara manual, mulai dari proses pembuatan absensi, proses pengabsenan, hingga rekapitulasi dan pembuatan laporan.

2. Proses pengolahan data kehadiran di sekolah ini cukup rumit karena cukup banyak keterlibatan berbagai pihak, proses pengolahan datanya cenderung memakan waktu lama. Output dari sistem kehadiran siswa ini berupa laporan untuk kepala sekolah.

3. Oleh karena itu dibuatlah rancangan sistem kehadiran siswa dengan fasilitas fungsional sebanyak 25.

\section{SARAN}

Dalam penerapan sistem yang berjalan penulis ingin mengemukakan beberapa saran agar sistem kehadiran siswa di SMKN 2 Kabupaten Tangerang bisa menjadi lebih baik, diantaranya:

1. Untuk mempermudah berbagai pihak disarankan adanya komputerisasi terhadap data kehadiran untuk mempercepat proses pengolahan data, juga tidak memakan banyak sumber daya.

2. Agar kedepanya pengolahan data kehadiran tidak memakan waktu yang lama, juga bentuk outputnya pun tak hanya bagi pihak sekolah namun bagi pihak murid juga agar sistem bisa menjadi lebih transparan bagi semua pihak yang terlibat.

3. Dikembangkan sistem ini secara mobile agar sistem dapat diakses dimana saja selama jam sekolah. Tentunya hal ini dapat mempermudah dalam pengolahan data, juga tidak memerlukan lagi banyak sumberdaya.

\section{DAFTAR PUSTAKA}

[1] https://kbbi.web.id/hadir (diakses pada selasa, 18 desember 2017).

[2] Taufiq Rohmat. 2013. Sistem Informasi Manajemen. Yogyakarta : Graha Ilmu.

[3] Kuswara Heri dan Deni kusmana. 2017. Sistem Informasi Absensi Siswa Berbasis Web Dengan Sms Gateway Pada Sekolah Menengah Kejuruan Al - Munir Bekasi. Bekasi : Indonesian Jurnal on Network and Security.

[4] Widhiarso Yoni dan Berliana Kusuma Riasti. 2013. Rancang Bangun Sistem Informasi Nilai Akademik dan Presensi Siswa Berbasis SMS Gateway pada SDN Tulakan III. Bekasi :Indonesian Jurnal on Network and Security.

[5] Adam Wahyu dan Lamhot Sagala. 2014. Sistem Absensi Pegawai Menggunakan Teknologi RFID. Bandung : STMIK LPKIA.

[6] Nuh Muchamad. 2012.Pembangunan Sistem Informasi Presensi Siswa Pada Sekolah Menengah Atas (SMA) Negeri 1 Rembang Berbasis Fingger Print. Bekasi: Indonesian Jurnal on Network and Security Volume 4 No 4 - 2012.

[7] Syarah, Sri Rahayu dan Arie Fiyan Wira Wisena. 2012.Perancangan Sistem Informasi Absensi Staf dan Guru Pada SMA Bina Insani Berbasis Web . Tangerang : Eksplora Informatika. 